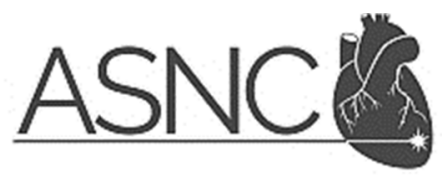

\title{
DIAGNOSTIC YIELD OF 18F-FDG PET/CT IN SUSPECTED DIAGNOSIS OF VASCULAR GRAFT INFECTION: A PROSPECTIVE COHORT STUDY
}

\begin{tabular}{|c|c|}
\hline Journal: & Journal of Nuclear Cardiology \\
\hline Manuscript ID & JNC-18-069-OA.R2 \\
\hline Manuscript Type: & Original Article \\
\hline Date Submitted by the Author: & 04-Jun-2018 \\
\hline Complete List of Authors: & $\begin{array}{l}\text { Bowles, Hans } \\
\text { Ambrosioni, Juan; Hospital Clinic de Barcelona, Infectious Diseases Service } \\
\text { Mestres, Gaspar; Hospital Clinic de Barcelona, Cardiovascular Surgery } \\
\text { Department } \\
\text { Hernández-Meneses, Marta; Hospital Clinic de Barcelona, Infectious } \\
\text { Diseases Service } \\
\text { Sánchez, Nuria; Hospital Clinic de Barcelona, Nuclear Medicine } \\
\text { Llopis, Jaime; University of Barcelona, Statistics Department } \\
\text { Yugueros, Xavier; Hospital Clinic de Barcelona, Cardiovascular Surgery } \\
\text { Department } \\
\text { Almela, manel; Hospital Clinic de Barcelona, Clinical Microbiology } \\
\text { Department } \\
\text { Moreno, Asunción; Hospital Clinic de Barcelona, Infectious Diseases Service } \\
\text { Riambau, Vicenç; Hospital Clinic de Barcelona, Cardiovascular Surgery } \\
\text { Department } \\
\text { Fuster, David; Hospital Clinic de Barcelona, Nuclear Medicine } \\
\text { Miró, José; Hospital Clinic de Barcelona, Infectious Diseases Service }\end{array}$ \\
\hline Keywords: & $\begin{array}{l}\text { Infection }<\text { Diseases/processes, PET }<\text { Modalities, Vascular imaging }< \\
\text { Tests, Diagnostic and prognostic application }<\text { Outcomes }\end{array}$ \\
\hline
\end{tabular}


TITLE: DIAGNOSTIC YIELD OF ${ }^{18}$ F-FDG PET/CT IN SUSPECTED DIAGNOSIS OF VASCULAR GRAFT INFECTION: A PROSPECTIVE COHORT STUDY

\author{
Hans Bowles ${ }^{1 *}$, Juan Ambrosioni ${ }^{2,6 *}$, Gaspar Mestres ${ }^{3}$, Marta Hernández-Meneses², Nuria Sánchez ${ }^{1}$, \\ Jaime LLopis ${ }^{4}$, Xavier Yugueros ${ }^{3}$, Manel Almela ${ }^{5}$, Asuncion Moreno ${ }^{2,6}$, Vicenç Riambau ${ }^{3}$, David \\ Fuster $^{1,6}$, Jose M Miro ${ }^{2,6}$, Hospital Clinic Endocarditis Study Group $†$. \\ ${ }^{1}$ Nuclear Medicine Department, Hospital Clinic, Barcelona, Spain. \\ ${ }^{2}$ Infectious Diseases Service, Hospital Clinic, Barcelona, Spain. \\ ${ }^{3}$ Cardiovascular Surgery Department, Hospital Clinic, Barcelona, Spain. \\ ${ }^{4}$ Statistics Department, Faculty of Biology, University of Barcelona, Barcelona, Spain. \\ ${ }^{5}$ Clinical Microbiology Department, Hospital Clínic, Barcelona, Spain. \\ ${ }^{6}$ Institut d'InvestigacionsBiomèdiques Pi i Sunyer (IDIBAPS), University of Barcelona, Barcelona, Spain. \\ ${ }^{\dagger}$ Members of the Hospital Clínic Endocarditis Study Group are listed in the Appendix. \\ *Equivalent merits
}

\author{
Correspondence address: \\ David Fuster, MD PhD. \\ Nuclear Medicine Department. \\ Hospital Clínic i Provincial de Barcelona \\ Villarroel, 170 \\ 08036 Barcelona \\ SPAIN \\ E-mail: dfuster@clinic.cat
}




\begin{abstract}
Background: Prosthetic vascular graft infection (PVGI) is a severe complication associated with high morbidity and mortality. Clinical diagnosis is complex, requiring image testing such as CT angiography or leukocyte scintigraphy, which have considerable limitations. The aim of this study was to know the diagnostic yield of PET/CT with ${ }^{18}$ F-Fluorodeoxyglucose $\left({ }^{18} \mathrm{~F}-\mathrm{FDG}\right)$ in patients with suspected PVGI. Methods: We performed a prospective cohort study including 49 patients with suspected PVGI, median age of $62 \pm 14$ years. Three uptake patterns were defined following published recommendations: (i) focal or (ii) patched (PVGI criteria) and (iii) diffuse (no PVGI criterion). Results: Sensitivity, specificity, and positive and negative predictive values for ${ }^{18} \mathrm{~F}-\mathrm{FDG}$ PET/CT were $88 \%, 79 \%, 67 \%$ and $93 \%$, respectively. ${ }^{18}$ F-FDG PET/CT identified $14 / 16$ cases of PVGI showing a focal $(n=10)$ or patched pattern $(n=4)$, being true negative in $26 / 33$ cases with either a diffuse pattern $(n=16)$ or without uptake $(n=10)$. Five of the seven false positive cases $(71 \%)$ showed a patched pattern and all coincided with the application of adhesives for PVG placement. Conclusions: ${ }^{18} \mathrm{~F}-\mathrm{FDG}$ PET/CT is a useful technique for the diagnosis of PVGI. A patched pattern on PET/CT in patients in whom adhesives were applied for prosthetic vascular graft placement does not indicate infection.
\end{abstract}

Keywords: Fluorodeoxyglucose (FDG), Diagnostic and prognostic application, PET/CT imaging. 
1

2

3

4

5

6

7

8

9

10

11

12

13

14

15

16

17

18

19

20

21

22

23

24

25

26

27

28

29

30

31

32

33

34

35

36

37

38

39

40

41

42

43

44

45

46

47

48

49

50

51

52

53

54

55

56

57

58

59

60

\section{ABBREVIATIONS}

$\begin{array}{ll}\text { PVGI } & \text { Prosthetic vascular graft infection } \\ { }^{18} \text { F-FDG } & { }^{18} \text { F-Fluorodeoxyglucose } \\ \text { PTFE } & \text { Polytetrafluoroethylene } \\ \text { SUV } & \text { Computed Tomography } \\ \text { M-TBR } & \text { Standardized uptake value } \\ \text { AUC } & \text { Area under the receiver-operating characteristic curve } \\ \text { GNR } & \text { Gram-negative rods } \\ \text { PPV } & \text { Positive predictive value } \\ \text { NPV } & \text { Negative predictive value }\end{array}$

PVGI Prosthetic vascular graft infection

${ }^{\mathbf{1 8}}$ F-FDG $\quad{ }^{18}$ F-Fluorodeoxyglucose

Polytetrafluoroethylene

Footer Text 


\section{INTRODUCTION}

Prosthetic vascular graft infection (PVGI) is a severe complication, albeit relatively rare (incidence rate between $1 \%$ and $6 \%$ ), which may develop following reconstructive surgery. It requires immediate accurate diagnosis, and in some cases may lead to serious complications with mortality rates as high as $40 \%$ at five years according to the series (1-2). The risk of infection varies according to the location of the prosthesis: aortic grafts limited to the abdomen have a risk of around $1 \%$ whereas the percentage varies from $1.5 \%$ to $2 \%$ in the aortofemoral and may be of up to $6 \%$ in the infrainguinal arteries (1). Synthetic grafts are made of either Dacron or polytetrafluoroethylene (PTFE) and both materials may be used for endovascular implants and for open surgery. Dacron grafts are more susceptible to infections and are mainly used in large vessels in aortic and aortoiliac surgery, whereas PTFE peripheral implants are preferably used for medium and small vessels (3).

The diagnosis of prosthetic infection is based on the presence of clinical manifestations, laboratory, microbiological and imaging results. Several studies with computed tomography (CT)(1) have described very good diagnostic accuracy with this method in patients with advanced graft infection, reporting a sensitivity and specificity of around $94 \%$ and $85 \%$, respectively (4). However, CT usually fails to differentiate changes in the early period post- surgery and to detect low-grade infection, having a sensitivity and specificity about 55\% and 100\%, respectively (5).

The use of radiolabeled leukocytes has been quite successful in detecting low-grade PVGIs, but low resolution hinders their ability to differentiate adjacent soft tissue infections (6). Preliminary studies found ${ }^{18}$ F-FDG-PET to be more accurate compared to contrast CT but showing potential high ${ }^{18} \mathrm{~F}-\mathrm{FDG}$ uptake in non infected vascular grafts requiring PET/CT findings to be interpreted with caution (7-8). Thereafter, other groups suggested the higher sensitivity and specificity of PET/CT using focal and diffuse patterns trying to differentiate infection from inflammatory and/or physiologic uptake (9-10). However, more recent studies have coincided in the need to define non homogeneous or patched uptake patterns (11-12) and the degree of uptake (13) necessary to establish a differential diagnosis of PVGI. Other relevant technical aspects to correctly interpret PET/CT findings include the progressive use of surgical adhesives which produce severe active inflammation surrounding the glue remnant and show 
increased heterogeneous ${ }^{18} \mathrm{~F}$-FDG uptake making it difficult to distinguish between PVGI or inflammatory changes (3). In this context, a study by Guenther et al showed a surprisingly low specificity for PET/CT in the diagnosis of infection of the proximal thoracic aorta (14). A case definition was recently proposed for aortic graft infections, with PET/CT being considered as a minor criterion (15).

The primary aim of this study was to evaluate the diagnostic yield of PET/CT in patients with suspected PVGI. The secondary aims were to determine the usefulness of PET/CT to discriminate between PVGI and infectious processes of adjacent tissues and the influence of bioglue in ${ }^{18} \mathrm{~F}$-FDG uptake. 


\section{MATERIALS AND METHODS}

\section{Patients and Design}

We performed a prospective cohort study from 49 consecutive patients with suspected PVGI attended in an 850-bed university hospital from June 2014 to July 2016.Since 1979, all patients with PVGI attended at the Hospital Clinic of Barcelona have been managed by a multidisciplinary group which meets on a weekly basis. Patients were classified in line with the Samson Classification for vascular graft infection according to the depth of infection and degree of graft involvement (16). The study was approved by the Institutional Review Board and written informed consent to perform PET/CT was obtained from all the patients included.

Diagnosis of PVGI was confirmed by clinical/surgical, radiologic and laboratory findings in the presence of a single major criterion (pus, exposed graft, fistula, perigraft fluid or gas on $\mathrm{CT}$ and organisms recovered from graft or perigraft fluid), plus any other criterion major or minor (localized clinical features, fever, radiological suspicion of a related infection, positive blood cultures and elevated inflammatory markers), as described in the literature by Lyons et al (15). PET/CT was not used for PVGI diagnosis to ensure that there was no influence on the outcomes. PVGI was ruled out by a combination of biochemical, clinical, and imaging parameters (other than PET/CT) and a minimum follow-up of six months.

\section{PET/CT}

Whole-body scans were performed using a hybrid PET/CT (SIEMENS Biograph mCT 64S). The patients underwent a 6-h fast period with blood glucose levels less than $140 \mathrm{mg} / \mathrm{dl}$ prior to the intravenous administration of $0.11 \mathrm{mCi}(4.07 \mathrm{MBq}) / \mathrm{kg}$ of $18 \mathrm{~F}-\mathrm{FDG}$. During the acquisitions, patients were in supine position with their arms raised above their head. Whole-body PET data were acquired $1 \mathrm{~h}$ after ${ }^{18} \mathrm{~F}$-FDG administration in 3D mode and for 3 minutes per bed position. PET images were reconstructed using the ordered-subsets expectation maximization algorithm with and without CT data for attenuation correction. PET, CT, and fused PET/CT images were available for review and shown in axial, coronal, and sagittal planes. 


\section{Image Interpretation}

Images were interpreted separately by two nuclear medicine specialists trained in infection and

${ }^{18}$ F-FDG PET/CT. Disagreements were settled by consensus with a third nuclear medicine specialist. Foci of increased ${ }^{18}$ F-FDG uptake were recorded. Three uptake patterns were defined visually following published recommendations: (i) focal (one dominant area of uptake) or (ii) inhomogeneous or patched (PVGI criteria) and (iii) diffuse or homogenous (no PVGI criterion) (9) ${ }^{18}$ F-FDG uptake in the region of the vascular graft was evaluated with $3 \mathrm{D}$ and volume rendering image fusion using software based on the Unix system to visually establish the uptake pattern and if the ${ }^{18} \mathrm{~F}-\mathrm{FDG}$ uptake corresponded to the vascular graft or to the adjacent tissues (Osirix, Pixmeo, Geneva, Switzerland).

Additionally, a semi-quantitative analysis was made using the maximum standardized uptake value (SUVmax) in a spherical volume of interest area of suspected infection. The mean standard uptake value (SUVmean) was obtained in the blood pool using superior cava vein uptake. A Maximum target-toblood pool ratio (M-TBR) was calculated by dividing the SUVmax of the area of interest by the SUVmean of the blood pool.

\section{Statistical Analysis}

The statistical analyses were performed using the SPSS, version 22.0 (SPSS Inc.). The sensitivity and specificity and the positive (PPV) and negative predictive values (NPV) were calculated. Inter-rater agreement with Kappa statistics was obtained. Areas under the receiver-operating characteristic curve (AUC) and total and sensitivity optimization thresholds were calculated. Differences in continuous and categorical variables on table 1 were measured by Kruskal-Wallis test and by $\chi^{2}$ test, respectively. A two-sided p-value $<0.05$ was considered significant. 


\section{RESULTS}

Table 1 shows the baseline characteristics of the patients. The mean age \pm standard deviation (SD) of the patients recruited (42 men and 7 women) was $62 \pm 14$ years. The median time span between PVG placement and PET/CT was six months (interquartile range $[\mathrm{IQR}]=2-36$ ), and 44 patients $(90 \%)$ received antibiotics before PET/CT. A final diagnosis of PVGI was established in 16 patients: with infection of the ascending aorta $(n=2)$, aortobifemoral $(n=3)$, aortoiliac $(n=1)$, axillofemoral $(n=1)$, femoral $(\mathrm{n}=2)$, femoropopliteal $(\mathrm{n}=5)$ and other locations $(\mathrm{n}=2)$. See Table 2. All 16 patients classified as PVGI had at least one major and one minor criterion based on the case definition by Lyons et al (15). Following Samson classification, nine out the 16 patients with confirmed PVGI were in group $4(n=5)$ orgroup $5(n=4)$. Eight patients were diagnosed with infection of adjacent tissues not related to the PVG.The causative microorganism was identified in 15 out of 16 infections, with coagulase- negative Staphylococci $(\mathrm{n}=4)$ and polymicrobial isolates $(\mathrm{n}=4)$ being the most frequent (Table 2).

In our series, ${ }^{18}$ F-FDG PET/ CT was able to identify 14/16 cases of PVGI (Figure 1) showing a focal $(n=10)$ or patched pattern $(n=4)$ and was true negative in 26/33 cases with either a diffuse pattern $(\mathrm{n}=16)$ or without uptake $(\mathrm{n}=10)$. The remaining $7 / 33$ non infected cases were considered as false positive results and showed a patched $(n=6)$ or focal $(n=1)$ uptake. The sensitivity, specificity, PPV and NPV for

${ }^{18}$ F-FDG PET/CT were $88 \%, 79 \%, 67 \%$ and $93 \%$, respectively. Two false negative cases were found in the ascending aorta and in the femoral PVG. The duration of antibiotic use in these two cases was 18 and 14 days, and the mean duration in PVGI group was 15 days (see Table 1). Five out of the 7 false positive cases $(71 \%)$ showed a patched pattern ( 2 cases in the anastomotic site and 3 cases throughout the vascular graft), coinciding with the application of adhesives for PVG placement (Figure 2). When these cases were excluded from the analysis, these PET/CT values rose to up to $88 \%, 93 \%, 87 \%$ and $93 \%$, respectively. Additionally, PET/CT identified all the extra-prosthetic infections not identified by other procedures in the area surrounding the vascular graft: abscesses $(n=2)$, aneurysm $(n=3)$, infected hematoma $(n=2)$ and sternal osteomyelitis $(n=1)$. These cases represented $16 \%$ of the total number of patients and PET/CT was determinant in establishing that the infection was not related to the PVG (Figure 3).

Footer Text 
1

2

3

4

5

6

7

8

9

10

11

12

13

14

15

16

17

18

19

20

21

22

23

24

25

26

27

28

29

30

31

32

33

34

35

36

37

38

39

40

41

42

43

44

45

46

47

48

49

50

51

52

53

54

55

56

57

58

59

60

Quantitative analysis for PET/CT using AUC showed that the best thresholds to discriminate between infection and inflammatory and/or physiological uptake were a SUVmax $=4.2(75 \%, 78.79 \%)$ and a M-TBR $=1.83(93.75 \%, 66.67 \%)($ Figure 4$)$.

There was an agreement between the two observers to establish ${ }^{18} \mathrm{~F}$-FDG uptake pattern as patched, focal or diffuse in 38 of the $49(78 \%)$ cases. When considering only two categories as infected (patched and focal patterns) or not infected (diffuse pattern), the agreement rose to 45 out of 49 (92\%). The same analysis using Kappa statistics values to measure inter-rater agreement between operators were 0.618 (confidence interval [CI] 95\%; 0.420, 0.817) and 0.835 (CI 95\%; 0.681, 0.990), respectively. The Kappa coefficient was interpreted as having substantial agreement and almost perfect agreement, respectively. 


\section{DISCUSSION}

In this cohort of suspected PVGI, the focal ${ }^{18} \mathrm{~F}-\mathrm{FDG}$ uptake pattern on PET/CT was revealed as an accurate parameter for infection. However, the combination of inhomogeneous or patched pattern and the use of adhesives can be a source of false positive results. PVGI is associated with high mortality and morbidity making early accurate diagnosis essential in order to provide the most appropriate treatment. Diagnosis of cardiovascular infections is currently dependent on the presence of certain clinical symptoms and echocardiographical and CT angiography findings. CT angiography is considered the gold standard modality in patients with suspected PVGI. However, the characteristic signs such as local perigraft fluid retention and air bubbles are not always present in infected cases, and they cannot be interpreted as pathological in the early postoperative period (3 months) (10). Although the sensitivity of angio-CT is relatively high at $85-100 \%$, it may decrease in low-grade infections (17). Other post-surgical complications such as infected hematomas or pseudoaneurysms in the vicinity of the vascular graft may also make correct diagnosis difficult.

Several studies have shown that ${ }^{18}$ F-FDG may be a promising radiotracer for detecting cardiovascular infections (18-19). However, it should be noted that chronic aseptic inflammation in synthetic graft material, also constitutes a potential base for ${ }^{18} \mathrm{~F}-\mathrm{FDG}$ uptake, even long after surgery, which may potentially dificult the diagnosis of PVGI $(\mathbf{8}, \mathbf{1 3}, \mathbf{2 0})$. In a previous study Wasselius et al described ${ }^{18} \mathrm{~F}$-FDG uptake in vascular grafts of a vast majority of patients without graft infection indicating the possible high risk of a false-positive diagnosis (8). Saleem et al reported that ${ }^{18} \mathrm{~F}$-FDG uptake can remain long after surgery, being especially dependent on the prosthetic material used, especially with Dacron (21). Accordingly to previous data, we detected diffuse ${ }^{18}$ F-FDG uptake in up to $69 \%$ of our cases.

In a study of 33 patients with an aortic graft, Fukuchi et al. found one third to be infected, with false positive results as high as $36 \%$ (7). This also coincides with our series in which almost half of the non infected vascular grafts showed a diffuse uptake pattern (16 out of 33 cases). Keidar et al analyzed

${ }^{18}$ F-FDG uptake in non infected PVGs in 107 cases. They found ${ }^{18}$ F-FGDG uptake in $92 \%$ of patients, although none presented a focal pattern, supporting the concept that focal uptake is a strong indicator of 
graft infection (11). Nonetheless, we do not agree with these authors since the sensitivity in our study was $88 \%$ with a lower specificity of $79 \%$ for PVGI when either focal or patched uptake patterns of infection were present. As other authors $(\mathbf{1 2}, \mathbf{2 1 - 2 2})$, we did not find additional value of SUVmax or M-TBR to establish a threshold to discriminate inflammation from infection because of the rather low specificities with best optimal thresholds of SUVmax $=4.2(75 \%, 78.79 \%)$ and M-TBR $=1.83(93.75 \%, 66.67 \%)$, respectively.

Spacek et al were the first to report non homogeneous FDG uptake in $18.8 \%$ of cases, and of these $61 \%$ were infected and $39 \%$ were not. They therefore concluded that non homogeneous FDG uptake hampered the accuracy of PET/CT and must be considered as a non diagnostic result (12). These findings are crucial as focal and patched patterns can be difficult to differentiate as occurred in our series when the images were analyzed by two nuclear medicine specialists. This is important considering that the patched pattern can manifest as an inflammatory reaction and may not be due to an infectious process, especially in cases in which adhesives are necessary such as in open access for aortic root grafts, and some cases of endovascular aortic repair can show intense heterogeneous uptake $(\mathbf{7}, \mathbf{2 3})$. Taking this into account, positive PET/CT findings in patients with aortic root prosthesis should be interpreted with caution and monitoring with angio-CT is recommended (3). Our results in terms of specificity for ${ }^{18} \mathrm{~F}$ FDG PET/CT, significantly improved from $79 \%$ to $93 \%$ after excluding patients in whom adhesives had been applied for PVG placement from the analysis. There were only two false positive cases, one showing a patched and one a focal uptake pattern, which were indistinguishable from PVGI. An interesting case report by Ruiz-Zafra et al. concludes that false-positive 18F-FDG uptake as a result of a foreign body reaction can occur at any time during the follow-up period after lung cancer resection due to surgical adhesives (24). For all these reasons, we believe that surgical reports should detail the materials employed and the area(s) where they were used.

Combined PET/CT with volume render 3D images has also proved useful to discriminate between neighboring structures and allows the best resolution images to be obtained (25). This may be an interesting option to apply in the field of suspected PVGI to rule out infected pseudoaneurysms or hematomas close to the vascular graft. Indeed, we confirmed infection in the adjacent soft tissues of the suspected infected vascular graft showing a focal or heterogeneous uptake pattern in 8 cases of our series, 
representing a non negligible $16 \%$ of the cases. In all these cases, PET/CT was determinant in establishing if infection was related to the prosthetic graft as shown in figure 3. Other authors have reported similar difficulties in interpreting these findings, and this is important since inaccurate diagnosis may lead to the administration of inadequate treatment with a substantial potential morbi-mortality derived from unneeded PVG extractions (8-9). The use of antibiotics prior to PET/CT negative results may be induced by scanning during or directly after antibiotic therapy if all signs and symptoms have abated, as is initially reported by Scholtens et al. in a recent case report (26).However, the mean duration of antibiotherapy in the two false negative patients was no significantly longer than in the remaining cases of PVGI.

This study has several limitations. Firstly, patients with PVGI represent a heterogeneous population with different causal microorganisms, different prosthetic materials and different localizations of infection. Secondly, most of the patients in this series underwent antibiotic therapy prior to PET/CT and this may have influenced ${ }^{18} \mathrm{~F}$-FDG uptake and may be a cause of lower sensitivities, so prospective randomized larger series should be performed to analyze its effect. 
1

2

3

4

5

6

7

8

9

10

11

12

13

14

15

16

17

18

19

20

21

22

23

24

25

26

27

28

29

30

31

32

33

34

35

36

37

38

39

40

41

42

43

44

45

46

47

48

49

50

51

52

53

54

55

56

57

58

59

60

\section{NEW KNOWLEDGE GAINED}

This is to our knowledge the first study with series of patients raising that PET/CT do not allow to distinguish between inflammation and infection in vascular grafts with surgical use of adhesives. Furthermore, our findings provide valuable guidelines regarding the interpretation of the different patterns of PET/CT uptake in the clinical management of PVGI. 


\section{CONCLUSIONS}

PET/CT with ${ }^{18} \mathrm{~F}-\mathrm{FDG}$ is recommended for the diagnosis of suspected PVGI which can be well characterized based on focal and diffuse uptake patterns to distinguish between inflammation and PVGI. The use of adhesives can mimic a heterogeneous patched uptake of ${ }^{18} \mathrm{~F}-\mathrm{FDG}$ on PET/CT and consequently, these cases should be interpreted with caution as this pattern may also indicate the presence of inflammation. PET/CT can be recommended to ascertain PVG involvement versus soft tissue infection adjacent to the vascular graft, especially to exclude infected pseudoaneurysms or hematomas. 


\section{APPENDIX}

Investigators of the Hospital Clínic Infective Endocarditis Study Group: Jose M. Miró, Juan Ambrosioni, Juan M. Pericàs, Adrian Téllez, Marta Hernandez-Meneses, Asunción Moreno (Infectious Diseases Service); Cristina Garcia de la Mària, Javier Garcia-Gonzalez (Experimental Endocarditis Laboratory); Francesc Marco, Manel Almela, Jordi Vila (Microbiology Service); Eduard Quintana, Elena Sandoval, Juan C. Paré, Carlos Falces, Daniel Pereda, Ramon Cartañá, Salvador Ninot, Manel Azqueta, Marta Sitges, Barbara Vidal, José L. Pomar, Manuel Castella, José M. Tolosana, José Ortiz (Cardiovascular Institute); Guillermina Fita, Irene Rovira (Anesthesiology Department); David Fuster (Nuclear Medicine Service); Jose Ramírez, (Pathology Department); Mercè Brunet (Toxicology Service); Dolors Soy (Pharmacy Service); Pedro Castro (Intensive Care Unit), and Jaume Llopis (Department of Statistics, Faculty of Biology, University of Barcelona)

\section{FUNDING}

This work was supported by AGAUR 2014 SGR 279. Jose M. Miró received a personal 80:20 research grant from the Institutd'InvestigacionsBiomèdiques August Pi i Sunyer (IDIBAPS), Barcelona, Spain during 2017-19. The European Regional Development Fund (ERDF) "A way to build Europe" also provided funding.

\section{DISCLOSURE}

Potential financial conflicts of interest: Jose M. Miró has received consulting honoraria and/or research grants from AbbVie, Bristol-Myers Squibb, Cubist, Genentech, Medtronic, Novartis, Gilead Sciences, and ViiV Healthcare outside the submitted work. All other authors: none to declare. 


\section{REFERENCES}

1.- Baddour L, Bettmann M, Bolger A, Epstein AE, Ferrieri P, Gerber MA, et al. Nonvalvular Cardiovascular Device-Related Infections. Circulation 2003;108:2015-2031.

2.- Chiesa R, Astore D, Frigerio S, Garriboli L, Piccolo G, Castellano R, et al. Vascular prosthetic graft infection:epidemiology, bacteriology, pathogenesis and treatment. ActaChirBelg 2002;102:238-247.

3- Schouten LR, Verberne HJ, Bouma BJ, van Eck-Smit BL, Mulder BJ. Surgical glue for repair of the aortic root as a possible explanation for increased F-18 FDG uptake. J Nucl Cardiol 2008;15:146-147.

4- Orton D, LeVeen R, Saigh J, Culp WC, Fidler JL, Lynch TJ, et al. Aortic prosthetic graft infections: radiologic manifestations and implications for management. Radiographics 2000;20:977-993.

5- Low R, Wall S, Jeffrey R, Sollitto RA, Reilly LM, Tierney LM J. Aortoenteric fistula and perigraft infection evaluation with CT. Radiology 1990;175:157-162.

6- Erba PA, Leo G, Sollini M, Tascini C, Boni R, Berchiolli RN, et al. Radiolabelled leucocyte scintigraphy versusconventional radiological imaging for the management of late, low-grade vascular prosthesis infections. Eur J Nucl Med Mol Imaging 2014;41:357-368.

7- Fukuchi Ishida Y, Higashi M, Tsunekawa T, Tsunekawa T, Ogino H, Minatoya K, et al. Detection of aortic graft infection by fluorodeoxyglucose positron emission tomography: comparison with computed tomographic findings. J VascSurg 2005;42:919-925.

8- Wasselius J, Malmstedt J, Kalin B, Larsson S, Sundin A, Hedin U, et al. High 18F-FDG Uptake in synthetic aortic vascular grafts on PET/CT in symptomatic and asymptomatic patients. J Nucl Med 2008;49:1601-1605.

9- Keidar Z, Engel A, Hoffman A, Israel O, Nitecki S. Prosthetic vascular graft infection: the role of 18FFDG PET/CT. J Nucl Med 2007;48:1230-1236.

10- Brugging JL, Glaudemans AW, Saleem BR, Meerwaldt R, Alkefaji H, Prins TR, et al. Accuracy of FDG-PET-CT in the diagnostic work-up of vascular prosthetic graft infection. Eur J VascEndovasc Surg 2010;40:348-54.

11- Keidar Z, Pirmisashvili N, Leiderman M, Nitecki S, Israel O. 18F-FDG uptake in noninfected prosthetic vascular grafts: incidence, patterns, and changes over time. J Nucl Med 2014;55:392-395. 
1

2

3

4

5

6

7

8

9

12- Spacek M, Belohlavek O, Votrubova J, Sebesta P, Stadler P. Diagnostics of "non-acute" vascular prosthesis infection using 18F-FDG PET/CT: our experience with 96 prostheses. Eur J Nucl Med Mol Imaging 2009;36:850-858.

13- Berger P Vaartjes I, Scholtens A, Moll FL, De Borst GJ, De Keizer B, et al. Differential FDG-PET Uptake Patterns in Uninfected and Infected Central Prosthetic Vascular Grafts. Eur J VascEndovasc Surg 2015;50:376-383.

14- Guenther SP, Cyran CC, Rominger A, Saam T, Kazmierzcak PM, Bagaev E, et al. The relevance of 18F-fluorodeoxyglucose positron emission tomography/computed tomography imaging in diagnosing prosthetic graft infections post cardiac and proximal thoracic aortic surgery. Interact CardiovascThoracSurg 2015;21:450-458.

15- Lyons OT, Baguneid M, Barwick TD, Bell RE, Foster N, Homer-Vanniasinkam S, et al. Diagnosis of Aortic Graft Infection: A Case Definition by the Management of Aortic Graft Infection Collaboration (MAGIC). Eur J VascEndovascSurg 2016;52:758-763.

16- Samson RH, Veith FJ, Janko GS, Gupta SK, Scher LA. A modified classification and approach to the management of infections involving peripheral arterial prosthetic grafts. J VascSurg 1988;8:147-53.

17- Sah B Husmann L, Mayer D, Scherrer A, Rancic Z, Puippe G, et al. Diagnostic performance of 18FFDG-PET/CT in vascular graft infections. Eur J Vasc Endovasc Surg 2015;49:455-464.

18- Granados U, Fuster D, Pericas JM, Llopis JL, Ninot S, Quintana E, et al. Diagnostic Accuracy of 18F-FDG PET/CT in Infective Endocarditis and Implantable Cardiac Electronic Device Infection: A Cross-Sectional Study.J Nucl Med 2016;57:1726-1732.

19- Fernández-López R, de-Bonilla-Damiá A, Acevedo-Báñez I, Luque-Márquez R, Borrego-Dorado I. Usefulness of 18F-FDG PET/CT in a case of suspected vascular graft infection. Rev Esp Med Nucl Imagen Mol 2017;36:185-188.

20- Jamar Buscombe J, Chiti A, Christian PE, Christian PE, Delbeke D, Donohoe KJ, et al. EANM/SNMMI guideline for 18F-FDG use in inflammation and infection. J Nucl Med 2013;54:647-658. 21- Saleem BR, Pol RA, Slart RH, Reijnen MM, Zeebregts CJ. 18F-Fluorodeoxyglucose positron emission tomography/CT scanning in diagnosing vascular prosthetic graft infection. Biomed Res Int 2014;2014:471971.

22- Abidov A, D'agnolo A, Hayes SW, Berman DS, Waxman AD. Uptake of FDG in the area of a recently implanted bioprosthetic mitral valve. ClinNucl Med 2004;29:848. 
23- Pizzi MN, Roque A, Cuéllar-Calabria H, Fernández-Hidalgo N, Ferreira-González I, González-Alujas MT, et al. ${ }^{18}$ F-FDG-PET/CTA of Prosthetic Cardiac Valves and Valve-Tube Grafts: Infective Versus Inflammatory Patterns.JACC Cardiovasc Imaging 2016;9:1224-1227.

24-Ruiz-Zafra J, Rodríguez-Fernández A, Sánchez-Palencia A, Cueto A. Surgical adhesive may cause false positives in integrated positron emission tomography and computed tomography after lung cancer resection.Eur J Cardiothorac Surg. 2013;43:1251-1253.

25- Bowles H, Sánchez N, Tapias A, Paredes P, Campos F, Bluemel C, et al. Radioguided surgery and the GOSTT concept: From pre-operative image and intraoperative navigation to image-assisted excision. Rev Esp Med Nucl Imagen Mol 2017;36:175-184.

26- Scholtens AM, van Aarnhem E, Budde, RP. Effect of antibiotics on FDG-PET/CT imaging of prosthetic heart valve endocarditis. Eur Heart J Cardiovasc Imaging. 2015;16:1223. 
1

2

3

4

5

6

7

8

9

\section{TABLES}

Table 1: Demographic characteristics of the study group.

\begin{tabular}{|c|c|c|c|c|}
\hline Characteristics & $\begin{array}{c}\text { All cases } \\
(n=49) \\
\end{array}$ & $\begin{array}{c}\text { Confirmed PVGI } \\
(n=16) \\
\end{array}$ & $\begin{array}{c}\text { PVGI ruled out } \\
(n=33) \\
\end{array}$ & $\mathbf{P}$ \\
\hline Mean age (years) & $62 \pm 14$ & $61 \pm 14$ & $63 \pm 13$ & 0.62 \\
\hline \multicolumn{5}{|l|}{$\operatorname{Sex}, n(\%)$} \\
\hline Female & $7(14 \%)$ & $2(12 \%)$ & $5(15 \%)$ & 0.45 \\
\hline Male & $42(86 \%)$ & $14(88 \%)$ & $28(85 \%)$ & 0.04 \\
\hline \multicolumn{5}{|l|}{ Vascular prosthesis } \\
\hline \multicolumn{5}{|l|}{ Location } \\
\hline Ascending aorta & 16 & 2 & 14 & 0.004 \\
\hline Axillofemoral & 4 & 1 & 3 & 0.62 \\
\hline Aortobifemoral & 9 & 3 & 6 & 0.51 \\
\hline Aortoiliac & 7 & 1 & 6 & 0.12 \\
\hline Femoropopliteal & 6 & 5 & 1 & 0.22 \\
\hline Others & 7 & 4 & 3 & 0.97 \\
\hline \multicolumn{5}{|l|}{ Material } \\
\hline Dacron & 23 & 6 & 17 & 0.007 \\
\hline PTFE & 22 & 10 & 12 & 0.81 \\
\hline TAVI & 4 & - & 4 & 0.125 \\
\hline \multicolumn{5}{|l|}{ Treatment option } \\
\hline Open surgery & 39 & 14 & 25 & 0.56 \\
\hline Endovascular & 8 & 2 & 6 & 0.10 \\
\hline Hybrid surgery & 2 & 0 & 2 & 0.11 \\
\hline BioGlue & 12 & 4 & 8 & 0.39 \\
\hline AngioCT & 24 & 8 & 16 & 0.15 \\
\hline $\begin{array}{l}\text { Median time from vascular graft } \\
\left(I Q R^{+}\right), \text {months }\end{array}$ & $6(2-22)$ & $10.5(4-31)$ & $4(1-20)$ & 0.16 \\
\hline \multicolumn{5}{|l|}{ Antibiotics prior to PET/CT } \\
\hline Yes & 44 & 15 & 29 & 0.52 \\
\hline Duration (days)(mean, SD) & $14 \pm 5$ & $13 \pm 4$ & $16 \pm 7$ & 0.33 \\
\hline
\end{tabular}


Table 2: Clinical presentation, microbiological findings and outcome of the sixteen patients with confirmed diagnosis of PVGI.

\section{Clinical \& laboratory data}

n (\%)

- Intermittent claudication

- Traumatic vascular graft injury

- C-reactive protein, $\mathrm{mg} / \mathrm{dL}$ (mean, SD)

- Erythrocyte sedimentation rate(mean, SD)

$8.1 \pm 9.1$

$42 \pm 37$

- Leukocytes, *10 $10^{9} / \mathrm{L}$ (mean, SD)

6.5. \pm 3.2

Causal microorganisms

- Staphylococcus aureus

- CoNS

$4(25)$

- Polymicrobial

$4(25)$

- GNR

$2(12.5)$

- Enterococcus faecalis

$2(12.5)$

- Escherichia coli

$2(12.5)$

- Not identified

$1(6.25)$

\section{Diagnosis criteria}

- Clinical/Surgical

Pus

Exposed graft

Fistula

Graft insertion in an infected site*

$3(18.75)$

$4(25)$

$6(38)$

Localized clinical features of PVGI*

- $\underline{\text { Radiological }}$

Peri-graft fluid ( $\geq 3 \mathrm{mo}$ ) or gas $(\geq 7 \mathrm{mo}$ ) on CT

$4(25)$ Increase in peri-graft gas on serial imaging Other suspicious signs on $\mathrm{CT}^{*}$

Radiolabelled leukocyte uptake*

- Microbiological and laboratory

Organisms from explanted graft

$6(38)$

Organisms from intra-operative specimen

Organisms from percutaneous peri-graft fluid

Timing

- Early ( $<3$ months)

- Late ( $\geq 3$ months)

CoNS: coagulase-negative staphylococcus. GNR: Gram-negative rods.

PVGI: Prosthetic vascular graft infection.

*Minor criteria 


\section{FIGURE LEGENDS}

Figure 1: Example of a diffuse uptake pattern (arrowheads) with a dominant area of focal uptake (arrows) with a SUVmax of 6.7, shown in transverse and coronal PET (A) and fused PET/CT (B) images and considered as PVGI of the aortic bifemoral bypass. The vascular graft was removed and explant cultures were positive for coagulase-negative staphylococcus. 
Figure 2: This is a case of suspected infection of a hybrid thoracic graft, consisting of open replacement of the ascending aorta and aortic arch, with bioglue, and endoprosthesis in the descending aorta. Fused PET/CT images show patched (arrows) ${ }^{18} \mathrm{~F}-\mathrm{FDG}$ uptake (SUVmax $=8.3$ ) predominantly at the proximal end of the vascular graft (A, B). 3D PET images and volume rendering fusion images clearly demonstrated intense uptake in the site where adhesives were deposited, indicating that the uptake was due to inflammatory changes (C). Patient follow up confirmed the integrity of the vascular graft. 
Figure 3: Planimetry in the PET/CT coronal (A) and axial (B) axes shows a focal uptake suggestive of PVGI of a femoropopliteal by pass (arrows), which can be precisely located adjacent to the vascular graft after volume rendering image fusion $(\mathrm{C})$ corresponding to an infected hematoma (SUVmax $=5.2$ ). 
Figure 4: AUC including the sensitivity and specificity of the SUVmax (A) and the M-TBR (B).The best performansce points for ROC curves are shown by arrows. 


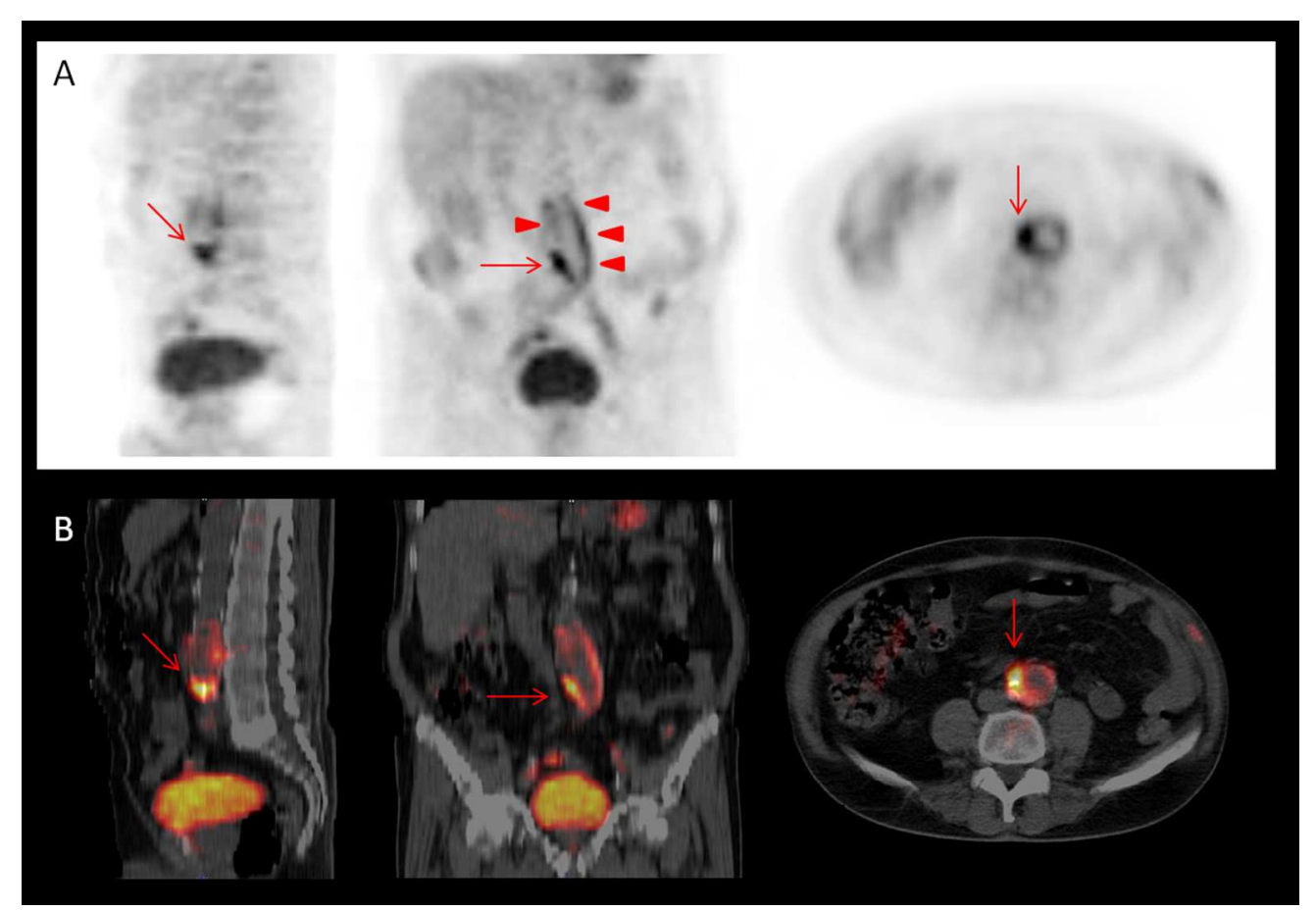

Figure 1

206x143mm (150 x 150 DPI) 


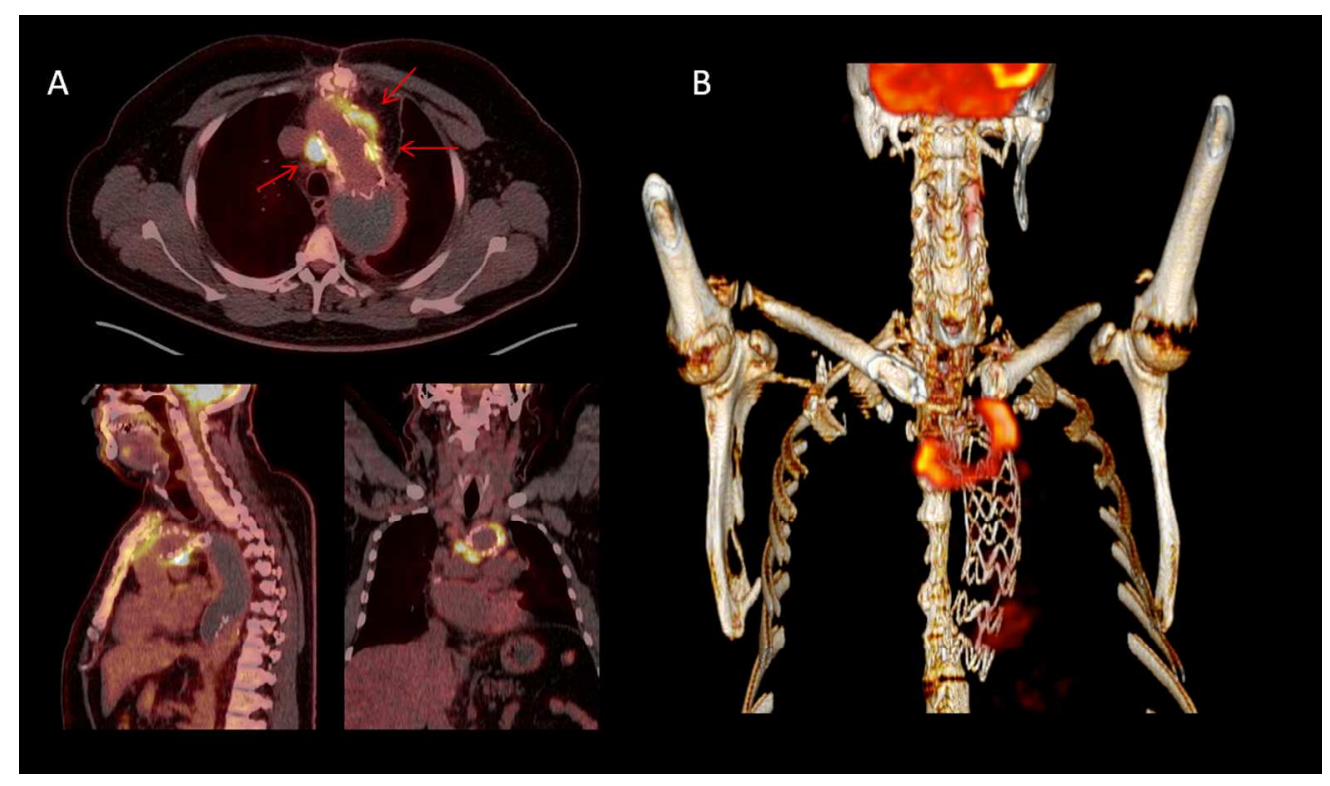

Figure 2

$218 \times 127 \mathrm{~mm}(150 \times 150 \mathrm{DPI})$ 


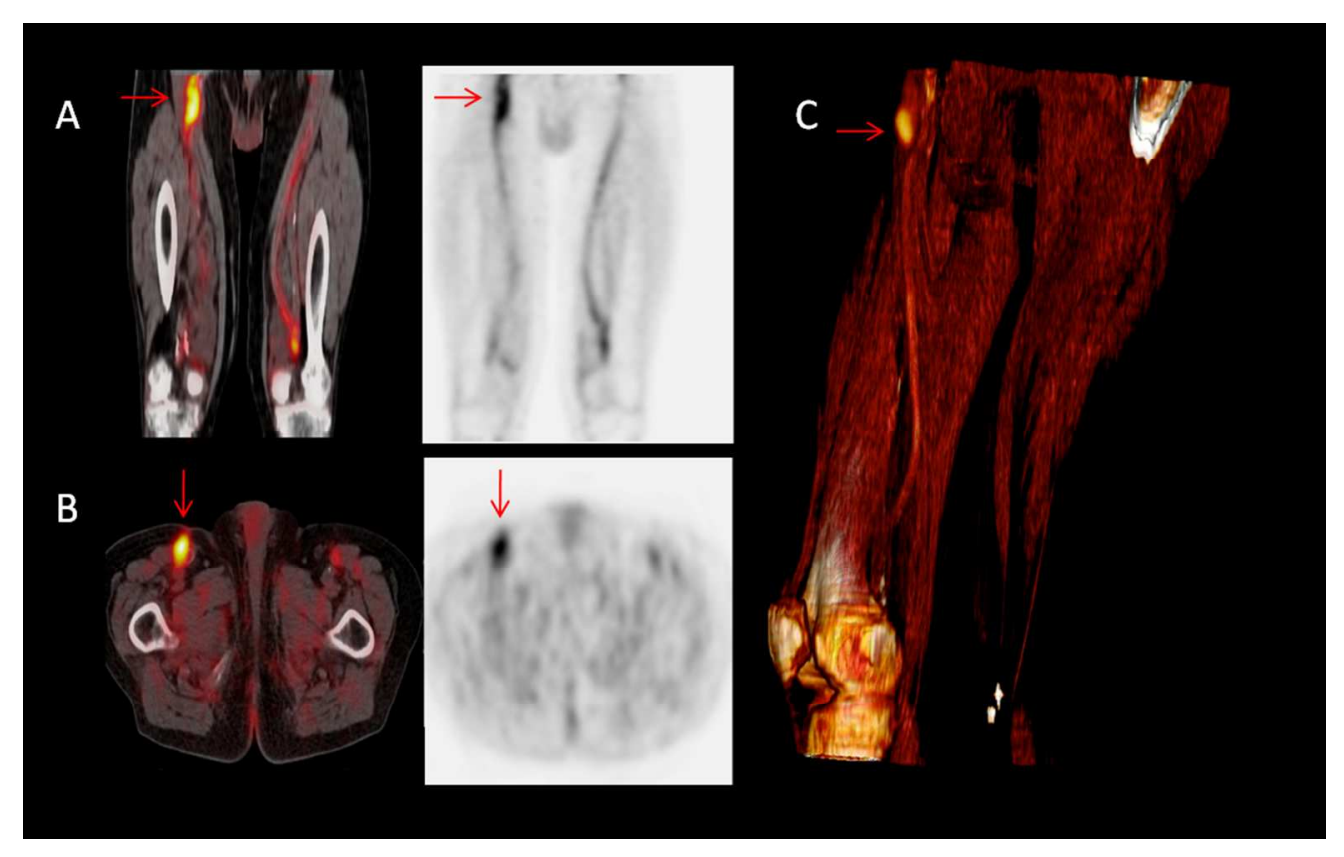

Figure 3

$190 \times 119 \mathrm{~mm}(150 \times 150 \mathrm{DPI})$ 


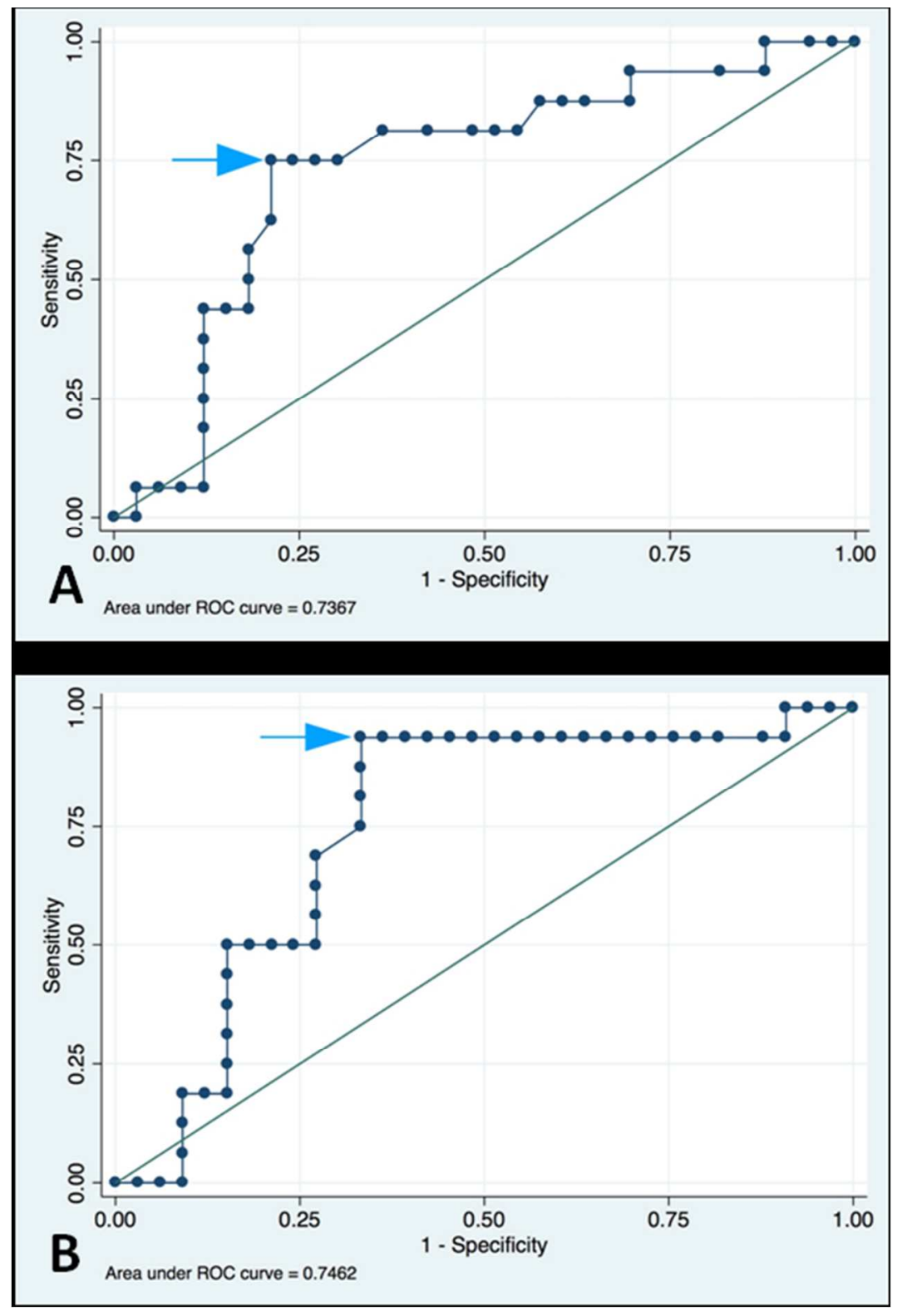

Figure 4

$95 \times 140 \mathrm{~mm}(150 \times 150 \mathrm{DPI})$

Footer Text 


\section{DIAGNOSTIC YIELD OF ${ }^{18}$ F-FDG PET/CT IN SUSPECTED DIAGNOSIS OF VASCULAR GRAFT INFECTION: A PROSPECTIVE COHORT STUDY}

Hans Bowles ${ }^{1 *}$, Juan Ambrosioni'2,6*, Gaspar Mestres ${ }^{3}$, Marta Hernández-Meneses², Nuria Sánchez ${ }^{1}$, Jaime LLopis ${ }^{4}$, Xavier Yugueros $^{3}$, Manel Almela ${ }^{5}$, Asuncion Moreno ${ }^{2,6}$, Vicenç Riambau'3, David Fuster ${ }^{1,6}$, Jose M Miro²,6, Hospital Clinic Endocarditis Study Groupt.

${ }^{1}$ Nuclear Medicine Department, Hospital Clinic. ${ }^{2}$ Infectious Diseases Service, Hospital Clinic. ${ }^{3}$ Cardiovascular Surgery Department, Hospital Clinic. ${ }^{4}$ Statistics Department, Faculty of Biology, University of Barcelona. ${ }^{5}$ Clinical Microbiology Department, Hospital Clínic. ${ }^{6}$ Institut d'Investigacions Biomèdiques Pi i Sunyer (IDIBAPS), University of Barcelona. Barcelona, Spain.

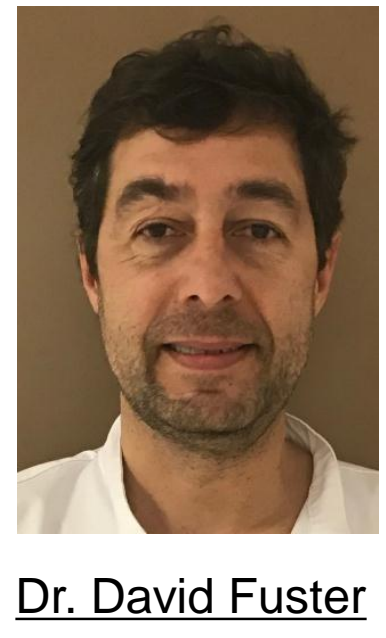

Copyright American Society of Nuclear Cardiology

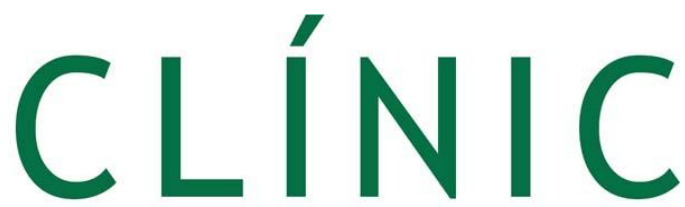

B A R C E L O N A Hospital Universitari 


\section{BACKGROUND}

1- Prosthetic vascular graft infection (PVGI) is a severe complication associated with high morbidity and mortality.

2- Clinical diagnosis is complex, requiring image testing such as CT angiography or leukocyte scintigraphy, which have considerable limitations.

3- The aim of this study was to know the diagnostic yield of $\mathrm{PET} / \mathrm{CT}$ with ${ }^{18} \mathrm{~F}$-Fluorodeoxyglucose $\left({ }^{18} \mathrm{~F}-\mathrm{FDG}\right)$ in patients with suspected PVGI. 


\section{METHODS}

A. Study type: Prospective cohort study.

B. Study subjects: 49 consecutive patients with suspected PVGI attended in an 850-bed university hospital from June 2014 to July 2016.

C. Study endpoints:

A. Primary end point(s): to evaluate the diagnostic yield of PET/CT in patients with suspected PVGI.

B. Secondary end point(s): to determine the usefulness of PET/CT to discriminate between PVGI and infectious processes of adjacent tissues and the influence of bioglue in ${ }^{18} \mathrm{~F}$-FDG uptake.

D. Study variables: maximum standardized uptake value (SUVmax) and ${ }^{18} \mathrm{~F}$ FDG uptake uptake patterns. 


\section{RESULTS}

- In our series, ${ }^{18}$ F-FDG PET/ CT was able to identify $14 / 16$ cases of PVGI showing a focal $(n=10)$ or patched pattern $(n=4)$ and was true negative in $26 / 33$ cases with either a diffuse pattern $(n=16)$ or without uptake $(n=10)$. The remaining $7 / 33$ non infected cases were considered as false positive results and showed a patched $(n=6)$ or focal $(n=1)$ uptake.

- The sensitivity, specificity, PPV and NPV for ${ }^{18}$ F-FDG PET/CT to diagnose PVGI were $88 \%, 79 \%$, $67 \%$ and $93 \%$, respectively.

- Five out of the 7 false positive cases (71\%) showed a patched pattern (2 cases in the anastomotic site and 3 cases throughout the vascular graft), coinciding with the application of adhesives for PVG placement. When these cases were excluded from the analysis, these PET/CT values rose to up to $88 \%, 93 \%, 87 \%$ and $93 \%$, respectively.

- Additionally, PET/CT identified all the extra-prosthetic infections not identified by other procedures in the area surrounding the vascular graft: abscesses $(n=2)$, aneurysm $(n=3)$, infected hematoma $(n=2)$ and sternal osteomyelitis $(n=1)$. 


\section{CONCLUSIONS}

1- PET/CT with ${ }^{18} \mathrm{~F}-\mathrm{FDG}$ is recommended for the diagnosis of suspected PVGI which can be well characterized based on focal and diffuse uptake patterns to distinguish between inflammation and PVGI.

2- The use of adhesives can mimic a heterogeneous patched uptake of ${ }^{18} \mathrm{~F}-\mathrm{FDG}$ on PET/CT and consequently, these cases should be interpreted with caution as this pattern may also indicate the presence of inflammation.

3- PET/CT can be recommended to ascertain PVG involvement versus soft tissue infection adjacent to the vascular graft, especially to exclude infected pseudoaneurysms or hematomas. 